\title{
Benefits of Mainstreaming Herbal Medicine in the Philippine Healthcare System
}

There are several problems that continue to plague the Philippine health care system. The cost of branded drugs in the Philippines is 22 times more than international reference prices while generic drugs are 4 times more. ${ }^{1}$ Despite price reductions due to legislations such as the Cheaper Medicines Act of 2008, as well as the Generics Act of 1988, those in the lower-income brackets still cannot afford maintenance medicines for hypertension and diabetes as well as antibiotics. ${ }^{2}$ Access to medicines and care from physicians and other healthcare professionals is especially challenging for geographically isolated and disadvantaged areas wherein the people are physically or economically inaccessible.

Filipino traditional medicine, of which herbal medicine plays a large role has been around for centuries and is wellaccepted in the rural areas. Validating the use of these traditional medicinal plants through research is essential in order to have an evidence-based practice of herbal medicine. The main areas of research can be defined as (1) herbal medicine quality and standardization, (2) preclinical pharmacological assessments and action mechanisms, and (3) clinical efficacy and safety assessments. ${ }^{3}$ These types of researches aimed at developing safe and efficacious, as well as low-cost Philippine herbal medicines, may well be a long-term solution to the obstacles to a healthy population cited above. Our Philippine medicinal plants are a valuable but often underappreciated resource with innumerable applications for non-communicable and communicable disease indications. Limited research in this field had long been ongoing in the Philippines. Support for this movement came with the passage of the Traditional and Alternative Medicine Act of 1997 which affirmed the commitment of the government towards the support and development of traditional medicine including herbal medicine. ${ }^{4}$ Another boost was the endorsement of the Department of Health of the Sampung Halamang Gamot in the 1990s. ${ }^{5}$ The World Health Organization has advocated the integration of Traditional Medicine within national health care systems and has urged governments to develop and implement national traditional medicine policies and programs especially with Universal Health Coverage. ${ }^{6}$

It was the National Integrated Research Program of the Philippines (NIRPROMP) who was at the forefront of this field and conducted the initial studies of these Ten Medicinal Plants. ${ }^{7}$ Many of them have been developed into modern formulations. These include Lagundi (Vitex negundo) tablet and syrup for cough and asthma, Sambong (Blumea balsamifera) tablet as a diuretic and treatment of urolithiasis, Tsaang gubat (Ehretia microphylla) tablet for gastrointestinal and biliary colic, Akapulco (Senna alata) lotion for cutaneous fungal infections, Yerba Buena (Mentha villosa) tablet as an analgesic, Ulasimang bato (Peperomia pellucida) tablet for the treatment of gout and hyperuricemia. Ampalaya (Momordica charantia) tablet was also developed as a glucose-lowering agent, but it is presently undergoing researches on the reformulated tablet. ${ }^{8}$ Several of the articles in this issue present evidence for the use of some of the mentioned medicinal plants. The NIRPROMP was the forerunner and is still an integral part of the Institute of Herbal Medicine.

Lagundi and Sambong have been integrated into the clinical practice of physicians in the Philippines, even by specialists. They have both been scientific and commercial successes. ${ }^{9}$ Their production has contributed to the revenue and growth of the Philippine Pharmaceutical Industry, as well as improved the economic status of farmers cultivating these crops. Developing more herbal medicines needed for primary health care would decrease our dependence on the importation of medicines, and increase the accessibility of drugs even in geographically isolated areas. Bringing back the herbal medicine gardens to the barangays in the rural communities will also assist in empowering the population. The integration of herbal medicines into mainstream clinical practice will only be possible if the researches performed, both non-clinical and clinical, are as robust as those for synthetic medicine.

\author{
Cecilia C. Maramba-Lazarte, MD \\ Director \\ Institute of Herbal Medicine \\ National Institutes of Health \\ University of the Philippines Manila
}


Benefits of Mainstreaming Herbal Medicine in the Philippine Healthcare System

\section{REFERENCES}

1. Paris J. Pharma Companies Offer to Cut Drug Prices [Internet] Rappler. 201925 October [cited 2020 Jan 15]. Available from https://www. rappler.com/nation/243372-pharmaceutical-companies-offer-cut-drug-prices.

2. Clarete RL, Llanto GM. 2017. Access to medicines in the Philippines: Overcoming the barriers [Internet]. Philippine Institute for Development Studies. 2017 [cited 2020 Jan 14]. Available from http://hdl.handle.net/11540/7967.

3. Zhang AL, Xue CC, Fong HH. Integration of Herbal Medicine into Evidence-Based Clinical Practice Current Status and Issues. In: Benzie IFF, Wachtel-Galor S, eds. Herbal Medicine: Biomolecular and Clinical Aspects, 2nd ed. Boca Raton (FL): CRC Press/Taylor \& Francis; 2011.

4. Traditional and Alternative Medicine Act (TAMA) of 1997, Republic Act No. 8423, Approved: December 9, 1997.

5. World Health Organization. Report of the Working Group on Herbal Medicines Meeting, March 1997.

6. World Health Organization. WHO Traditional Medicine Strategy: 2014-2023.

7. Eusebio JE, Umali BE. Inventory, documentation and status of medicinal plants research in Philippines. In: Batugal PA, Kanniah J, Young LS, Oliver JT, editors. Medicinal plants research in Asia, Volume 1: The framework and project workplans. Selangor DE, Malaysia: International Plant Genetic Resource Institute-Regional office for Asia, the Pacific and Oceania (IPGRI-APO), Serdang; 2004.

8. Purificacion J, Maramba N. Research Proposal Phase 1 Clinical Trial: Safety and Efficacy of Lyophilized Momordica charantia (Ampalaya) leaf tablet among Normal Volunteer Subjects (2018 version).

9. From Herbal Folklore to Modern Medicine [Internet]. World Intellectual Property Organization. 2013 [cited 2020 Jan 14]. Available from https://www.wipo.int/ipadvantage/en/details.jsp?id=3661. 